\title{
Richard Nobles and David Schiff (eds.), Law, Society and Community. Socio-Legal Essays in Honour of Roger Cotterrell
}

\author{
Thomas Riesthuis
}

Richard Nobles and David Schiff (eds.), Law, Society and Community. Socio-Legal Essays in Honour of Roger Cotterrell (Farnham: Ashgate, 2014), 361 p.

This captivating Festschrift contains contributions from well-known scholars from many fields of study in legal academia, all celebrating the work of Roger Cotterrell. The nineteen contributions to this volume are divided into three parts, namely 'socio-legal themes'; 'methodological and jurisprudential themes'; and 'globalization, cultural and comparative law themes', and are discussed in a thorough introduction by the editors. Cotterrell's work itself often transgresses disciplinary boundaries. The same can be said of many of the contributions to this volume. Philosophers of law, legal scholars, and socio-legal scholars discuss topics that are of interest to multiple disciplines and branches in legal academia. This mixture of approaches makes the three part division, which does not reflect this interdisciplinary vision or a strong focus on specific substantive issues, somewhat confusing. The three part division can also be confusing from the viewpoint of Cotterrell's own work. Authors who discuss Cotterrell's work on the concept of community, for example, are not confined to a specific part. Readers should nevertheless not be discouraged by the structure of the book because the contributions are all very enjoyable to read. In this review essay, I will further discuss two topics: different methodological approaches to the study of law and legal pluralism in legal theory. These two topics are of concern to multiple authors in this volume and seem the most interesting from the perspective of jurisprudence. The first topic concerns the relation between legal studies, socio-legal and theoretical research, and the second the strengths and weaknesses of a pluralist perspective in jurisprudence.

A first common theme discussed by authors in this volume is the relation between legal studies on the one hand and socio-legal studies and jurisprudence on the other hand. Nelken's contribution explores a lengthy debate between him and Cotterrell on the ways sociology could provide a more thorough understanding of law. In his article 'Why Must Legal Ideas be Interpreted Sociologically?' (Journal of Law and Society 25(2) (1998): 171-92), Cotterrell has argued that sociology is needed to fully understand law. Nelken challenges Cotterrell's claim that sociology could provide an understanding on the level of legal doctrine, meaning that sociology could, for example, clarify questions concerning the interpretation of provisions of legislation or a court's decision. Nelken has doubts whether this is possible with a sociological approach. Alternatively, Lobban's contribution pro- 
poses a historical instead of a sociological approach. Confusion at this point can arise on how legal studies could benefit from sociology and whether the legal doctrinal and socio-legal approaches are mutually exclusive. It does not seem to be the case that these approaches need to be mutually exclusive. In my opinion, Cotterrell's position on this subject matter also leaves room for both approaches. For him, a sociological approach to the study of law is not confined solely to sociological methods. Cotterrell's position entails a particular outlook on law and how to study it, a sociological outlook on his view, that seems to encompass both legal studies and socio-legal studies approaches. However, readers will not find clear illustrations of Cotterrell's sociological outlook in this volume that encompasses both approaches.

Closely related to this discussion on legal doctrinal and socio-legal approaches to the study of law is how jurisprudence, and in particular legal theory, should be situated in this constellation. In Cotterrell's work, for example, most recently in an article titled 'Why Jurisprudence is not Legal Philosophy' (Jurisprudence 5(1) (2014): 41-55), he has stressed the relevance of legal theory to legal practice and the role it should play in clarifying conceptual and theoretical problems encountered within that practice. On Cotterrell's account, jurisprudence brings us closer to a better understanding of law, meaning a better understanding of law that could benefit legal practitioners. This issue is also discussed by Nobles and Schiff in their contribution. In his contribution to the volume, Tamanaha challenges Cotterrell's standpoint. He maintains that generally legal theory does not bring us closer to a better understanding of law that would benefit legal practitioners. This is so because legal theorists are concerned with constructing theories of law. Tamanaha's view, however, is problematic if one accepts that legal theory is a critical reflection on legal doctrine and not solely occupied with theory. Legal philosopher Ronald Dworkin, for example, who Tamanaha mentions in his contribution, was also concerned with explaining how his philosophical reflections were important to the legal practice he aimed to understand. Tamanaha is sceptical about the practical relevance of legal theory and provides historical examples from American legal practice to illustrate this point. It is, however, difficult to comprehend what the object of inquiry of legal theory from Tamanaha's point of view is if legal theory only revolves around constructing theoretical models.

Finally, a number of contributions in this volume go into the relation between jurisprudence and socio-legal studies. Several authors engage with Cotterrell's views on socio-legal jurisprudence. Throughout his work, Cotterrell has connected sociology, and in particular sociological theory, with jurisprudence. A socio-legal jurisprudence requires a theory of law that is open to empirical data from sociolegal studies and empirical analyses of law that are theoretically sound. A sociolegal jurisprudence combines the two perspectives of socio-legal studies and jurisprudence. In their contribution to the volume, Taekema and Van der Burg intend to offer such a socio-legal jurisprudence with their theory of legal interactionism that builds on Lon Fuller and Philip Selznick's work and conceptualizes law in terms of social interactions. Luhmann's systems theory, on the other hand, dis- 
cussed by Nobles and Schiff in their contribution, can be seen as an example of why it could be difficult to fully achieve a socio-legal jurisprudence. Luhmann's systems theory is a sociological theory that conceptualizes law as one of multiple social systems in a society. This theory is first and foremost a sociological theory on law and not a legal theory. Fully bridging the gap between jurisprudence and socio-legal studies could therefore be difficult. This illustrates that the theoretical perspective one takes, e.g., a focus on social interactions or on social systems, entails certain views on the possibility of a socio-legal jurisprudence.

The previous discussion on the relation between different approaches to the study of law bears on the methodological foundations of legal theory and legal philosophy. Methodological assumptions regarding the object of inquiry or the aims of jurisprudence seem to affect how one characterizes the relation between the three approaches to the study of law. A socio-legal jurisprudence is difficult to conceive, for example, if one conceptualizes the object of inquiry of jurisprudence and socio-legal studies as radically opposed. Legal philosophers approach their subject with certain methodological assumptions, often influenced by the theoretical perspective that is taken. These assumptions on how law is to be philosophically analyzed should be made explicit, even more so if one does not rely on one single theoretical perspective. In this regard, Tamanaha's claim that legal doctrine does not benefit from conceptual insights of legal theory can be connected with his methodological assumptions. More generally, the contributions by Tamanaha, Lobban, Taekema, and Van der Burg; Nobles, and Schiff; and DouglasScott all in some way touch upon these methodological assumptions. Making these methodological assumptions explicit will help to explain one's approach to jurisprudence and its relation with other approaches to the study of law. Tamanaha seems to be the most aware of this issue.

A second common theme of interest of many authors in the volume is legal pluralism. In this volume, authors who discuss legal pluralism in their contributions develop the concept further in different and interesting ways often inspired by different strands of Cotterrell's work, such as his ideas on community as illustrated in Berman's and Eberhard's contributions. Douglas-Scott's contribution, for example, questions the ability of analytical jurisprudence to fully comprehend today's pluralist legal systems in which different legal orders are not neatly organized and structured. Berman's concept of 'global legal pluralism' signals the importance of international and transnational law for legal pluralism. Madsen's more sociological exploration of courts in international law implicitly adds to this perspective by examining how legal institutions such as courts function in legal systems. The authors in this volume are generally supportive of the pluralist perspective even though it can be difficult to fully incorporate this perspective in a theory of law. In particular, many theories of law aim to give a general account of the practice of law. Pluralism complicates this goal by showing that in many instances the practice of law lacks structure. The contributions in this volume provide some suggestions on how legal pluralism should be adequately incorporated in a theory of law but do not offer a thorough and detailed analysis. Fully 
exploring these lines of argument would, however, take considerably more space in this already rich volume. In sum, Law, Society and Community is a must-read for those interested in Cotterrell's ideas and legal philosophers with a particular interest in methodology and legal pluralism. 